LWSA

Local Wisdom, Social, and Arts

PAPER - OPEN ACCESS

\title{
Faktor-Faktor Penghambat Implementasi Kebijakan Penanggulangan Bencana Erupsi Gunung Sinabung
}

\author{
Author : Rudi Kristian \\ DOI $\quad: 10.32734 /$ lwsa.v1i1.149 \\ Electronic ISSN : 2654-7058 \\ Print ISSN : :2654-7066
}

Volume 1 Issue 1 - 2018 TALENTA Conference Series: Local Wisdom, Social and Arts

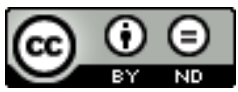

This work is licensed under a Creative Commons Attribution-NoDerivatives 4.0 International License.

Published under licence by TALENTA Publisher, Universitas Sumatera Utara
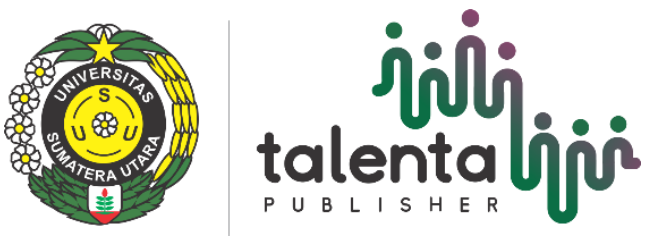


\title{
jibiti talenta ọioi TALENTA Conference Series

Available online at https://talentaconfseries.usu.ac.id

\section{Faktor-Faktor Penghambat Implementasi Kebijakan Penanggulangan Bencana Erupsi Gunung Sinabung}

\author{
Rudi Kristian $^{\mathrm{a}}$ \\ Fakultas Ilmu Sosial dan Ilmu Politik, Universitas Sumatera Utara, Medan-20155 \\ jondimitri77@gmail.com
}

\begin{abstract}
Abstrak
Bencana erupsi gunung Sinabung pertama kali terjadi tahun 2010, kemudian pada tahun 2013 sampai 2015 tidak berhenti erupsi. Ada kesan bahwa pemerintah tidak serius menangani penanggulangan bencana ini, mulai dari terlambatnya pembentukan BPBD Kabupaten Karo hingga tidak adanya rencana kontigensi bencana erupsi gunung Sinabung. Hal ini mendorong penulis untuk menganalisa faktor-faktor yang menghambat implementasi kebijakan penanggulangan bencana pada erupsi gunung Sinabung. Kebijakan penanggulangan bencana yang tertuang dalam Undang-Undang No. 24 Tahun 2007 tentang Sistem Penanggulangan Bencana harusnya dilakukan di semua daerah, terutama rawan bencana seperti Kabupaten Karo.Penelitian dilakukan di Kabupaten Karo dengan informan pemerintah Kabupaten, lembaga non pemerintah yag ikut terlibat penanganan bencana, BNPB dan akademisi yang merupakan ahli dan juga terjun langsung dalam penanganan bencana erupsi gunung Sinabung.

Penelitian ini menggunakan model analisis implementasi George Edward III, yang terdiri dari factor komunikasi, sumberdaya, disposisi dan struktur birokrasi. Penelitian ini menggunakan pendekatan kualitatif. Teknik pengumpulan data primer menggunakan wawancara. Hasil penelitian menunjukkan bahwa faktor disposisi pemerintah menjadi faktor paling dominan yang mempengaruhi faktor-faktor lainnya.
\end{abstract}

Kata Kunci: Kebijakan, implementasi, Penanggulangan bencana,

\section{Pendahuluan}

Dilihat dari kondisi geografisnya, tidak bisa dipungkiri Indonesia merupakan wilayah dengan ancaman bencana gempa bumi dan tsunami dengan intensitas yang cukup tinggi. Banyaknya gunung aktif dan negara yang berbentuk kepulauan adalah sebagian faktor yang mempengaruhi seringnya terjadi bencana di Indonesia. Secara geologis posisi Indonesia terletak diantara tiga lempeng tektonik besar, yaitu Lempeng Indo-Australia, Lempeng Eurasia dan Lempeng Pasifik.Menurut Loui (dalam Kodoatie, 2006), pertemuan lempeng-lempeng ini membuat Indonesia sebagai salah satu Negara yang paling banyak perubahan geologinya di dunia.

Menyikapi kondisi gepgrafis tersebut, mendorong pemerintah perlu mengeluarkan kebijakan yang fokus terhadap penanggulangan bencana. Kondisi ini membuat penanggulangan bencana menjadi fokus dalam Prioritas Pembangunan Nasional. Hal ini ditunjukkan dengan penerbitan Undang-Undang No 24 tahun 2007 tentang Penanggulangan Bencana dan tiga buah Peraturan Pemerintah lainnya sebagai amanat dari Undang-Undang No 24 Tahun 2007, yakni Peraturan Pemerintah No 21 Tahun 2008, Peraturan Pemerintah No 22 Tahun 2008 dan Peraturan Pemerintah No 23 Tahun 2008. Peraturan Pemerintah No. 21 Tahun 2008 tentang Penyelenggaraan Penanggulangan Bencana, mengatur wewenang penyusunan rencana penanggulangan bencana, dimana wewenang 
untuk Nasional ada pada Badan Nasional Penanggulangan Bencana (BNPB), untuk tingkat provinsi pada Badan Penanggulangan Bencana Daerah(BPBD) dan untuk tingkat Kabupaten/Kota pada Badan Penanggulangan Bencana Daerah Kabupaten/Kota.

Undang-undang No 24 Tahun 2007 ini merupakan komitmen pemerintah dalam penanganan bencana di daerah maupun Nasional.Undang-undang ini bertujuan untuk memberikan perlindungan terhadap kehidupan dan penghidupan termasuk perlindungan atas bencana, dalam rangka mewujudkan kesejahteraan umum yang berlandaskan Pancasila, sebagaimana diamanatkan dalam Undang-Undang Dasar Negara Republik Indonesia Tahun 1945(dalam Undang-Undang No 24 Tahun 2007).

\section{Tinjuan pustaka}

Implementasi kebijakan merupakan salah satu tahap yang sangat penting dari proses kebijakan. Namun implementasi sering dianggap hanya merupakan pelaksanaan dari keputusan pemerintah. Akan tetapi pada kenyataannya, tahap implementasi menjadi sangat penting karena sebuah kebijakan tidak akan menghasilkan apaapa bila tidak dapat dilaksanakan dengan baik dan benar. Dengan kata lain implementasi merupakan tahap dimana suatu kebijakan dilaksanakan secara maksimal sehingga bisa mencapai tujuan pembuatan kebijakan itu sendiri. Jika ingin mencapai apa yang diharapkan dari kebijakan, maka implementasi adalah syarat mutlak.

Edwards mengemukakan ada 4 (empat) faktor kritis yang mempengaruhi keberhasilan maupun kegagalan dari implementasi kebijakan. Yaitu; faktor Komunikasi, faktor Sumber daya, faktor Disposisi atau Sikap Pelaksana, dan faktor Struktur Birokrasi, yang keseluruhannya saling berhubungan dan saling mempengaruhi satu sama lain dalam menentukan keberhasilan maupun kegagalan implementasi.

Pertama, komunikasi, menurut Edwards (1980) harus ditransmisikan kepada personel yang tepat, dan harus jelas, akurat serta appropriate personnel. Edwards memberi penjelasan, bahwa apabila pembuat keputusan/decision maker mengharapkan agar implementasi kebijakan sesuai dengan yang apa yang diinginkan, maka ia harus memberikan informasi secara tepat. Menghindari diskresi/discretion pada para implementor merupakan komunikasi yang tepat. Diskresi ini tidak perlu dilakukan jika terdapat aturan yang jelas serta spesifik mengenai apa yang perlu dilakukan. Namun, aturan yang terlalu kaku juga dapat menghambat implementasi karena akan menyulitkan adaptasi dari para implementor.

Komunikasi merupakan proses penyampaian informasi dari komunikator (pemberi informasi) kepada komunikan (penerima informasi). Sementara itu, komunikasi kebijakan merupakan proses penyampaian informasi kebijakan dari pembuat kebijakan (policy makers) kepada pelaksana kebijakan (policy implementors) (Widodo, 2011), serta tanggapan dari pihak yang terlibat. (Nugroho, 2012)

Widodo (2011) mengatakan bahwa informasi perlu disampaikan kepada pelaku kebijakan agar pelaku kebijakan dapat memahami apa yang menjadi isi, tujuan, arah, kelompok sasaran (target group) kebijakan, sehingga pelaku kebijakan dapat mempersiapkan hal-hal apa saja yang berhubungan dengan pelaksanaan kebijakan, agar proses implementasi kebijakan bisa berjalan dengan efektif serta sesuai dengan tujuan kebijakan itu sendiri.

Komunikasi dalam implementasi kebijakan mencakup beberapa dimensi penting yaitu tranformasi informasi (transmisi), kejelasan informasi (clarity) dan konsistensi informasi (consistency). Dimensi tranformasi menghendaki agar informasi tidak hanya disampaikan kepada implementor kebijakan tetapi juga kepada kelompok sasaran dan pihak yang terkait. Dimensi kejelasan menghendaki agar informasi yang jelas dan mudah dipahami, selain itu untuk menghindari kesalahan interpretasi dari implementor kebijakan, kelompok sasaran maupun pihak yang terkait dalam implementasi kebijakan.Sedangkan dimensi konsistensi menghendaki agar informasi yang disampaikan harus konsisten sehingga tidak menimbulkan kebingungan implementor kebijakan, kelompok sasaran maupun pihak terkait.

Kedua, sumber daya, Edwards III (1980) menjelaskan bahwa hal yang diperlukan agar implementasi berjalan efektif adalah: Important resources include staff of the proper size and with the necessary expertise; relevant and adequate information on how to implement policies and on the compliance of others involved in implementation; the authority to ensure that policies are carried out as they are intended; and facilities (including buildings, equipment, land, and supplies) in which or with which to provide services. 
Jelas dan konsistennya perintah implementasi serta akuratnya perintah ditransmisikan, namun bila organisasi implementor yang mengimplementasikan kebijakan kekurangan sumber daya, maka implementasi tidak akan efektif. Sumber daya yang dimaksud oleh Edwards, sebagaimana disebutkan di atas meliputi staff, informasi, otoritas, dan fasilitas. Sumberdaya berupa staff tidak terbatas hanya pada sosok manusia, namun juga merupakan manusia yang memiliki skill yang dibutuhkan dalam implementasi kebijakan tersebut. Seringkali muncul kendala baru, secara kuantitas staff yang dimiliki cukup, namun dalam skill, staff tidak mencukupi. Sedangkan fasilitas yang dimaksud bisa berupa sarana, baik sarana fisik maupun pelatihan/pendidikan yang bertujuan untuk mendapatkan staff yang memiliki skill.

Ketiga, Edwards III memandang disposisi/sikap dari implementor sebagai faktor yang penting. Dalam hal ini Edwards III menekankan bahwa disposisi atau sikap merupakan hal yang penting karena apabila implementor kebijakan memiliki disposisi/sikap yang berlawanan dengan maksud kebijakan, maka hal ini dapat mengakibatkan ketidaksesuaian antara tujuan kebijakan yang sesungguhnya dengan implementasi kebijakan di lapangan. Nugroho (2012) menambahkan, skill implementor saja tidak cukup, kesediaan dan komitmen dari implementor juga diperlukan. Implementor yang sudah di fasilitasi pelatihan/pendidikan hingga memiliki skill yang sesuai dengan maksud dalam pelaksanaan kebijakan tidak serta merta membuat implementor akan melaksanakan tugasnya berhasil sesuai dengan maksud dari kebijakan yang dibuat. Jadi berguna tidaknya skill yang dimiliki oleh implementor sangat dipengaruhi oleh sikap implementor dalam melaksanakan tugasnya.

Resistensi/penolakan dari implementor bisa menimbulkan kebuntuan dalam implementasi, Edwards III menawarkan dua solusi alternatif, yakni yang pertama adalah dengan pergantian personel/implementor lapangan, sedangkan alternatif kedua adalah dengan memanipulasi insentif. (Edwards III, 1980). Mengganti personil/orang dalam birokrasi pemerintahan untuk melakukan implementasi merupakan hal yang sulit dan tidak menjamin bahwa proses implementasi bisa berjalan dengan baik, sehingga diperlukan alternative berupa pemberian insentif untuk mengatasi masalah tersebut.

Keempat adalah struktur birokrasi. Edwards III (1980) menyatakan bahwa dua sub variabel yang memberikan pengaruh besar pada birokrasi adalah Standard Operating Procedures (SOP) dan fragmentasi. SOP merupakan respon yang timbul dari implementor untuk menjawab tuntutan-tuntutan pekerjaan karena keterbatasan waktu dan sumber daya serta keinginan perlunya keseragaman dalam operasi organisasi yang kompleks. Dengan menggunakan bahasa yang singkat, Edwards III (1980) mendefinisikan fragmentasi merupakan penyebaran tanggungjawab dari suatu kebijakan pada beberapa unit organisasi.

Lebih lanjut Winarno (2007) menjelaskan bahwa fragmentasi merupakan penyebaran tanggungjawab suatu kebijakan kepada beberapa badan atau bagian yang berbeda sehingga memerlukan koordinasi.Dimana semakin besar koordinasi yang dibutuhkan dalam implementasi kebijakan, maka semakin kecil kemungkinan keberhasilan implementasi kebijakan tersebut.

Dari empat faktor akan menjadi indikator penelitian ini, dimana analisa terhadap faktor-faktor tersebut dilapangan akan menemukan faktor mana yang mempengaruhi dan menghambat implementasi kebijakan.

\section{Faktor-faktor yang mempengaruhi implementasi kebijakan penanggulangan bencana erupsi gunung sinabung}

Berdasarkan hasil penelitian, faktor-faktor yang mempengaruhi implementasi kebijakan penanggulangan bencana erupsi gunung Sinabung di Kabupaten Karo;

- Faktor disposisi/sikap implementor kebijakan terutama dalam hal respon terhadap kebijakan penanggulangan bencana merupakan penyebab utama buruknya implementasi kebijakan penanggulangan bencana di Kabupaten Karo. Hal ini berdampak buruk terhadap penanggulangan bencana erupsi gunung Sinabung. Disposisi pemerintah daerah sebagai implementor kebijakan tururt mempengaruhi faktor-faktor implementasi lainnya. Yakni faktor komunikasi, faktor struktur birokrasi dan faktor sumber daya.

- Faktor sumber daya implementor kebijakan. Keterbatasan sumber daya pemerintah baik dalam hal fasilitas, sarana dan prasarana, tenaga ahli dan pendanaan. Disposisi yang buruk atau resisten/menolak dan tidak sungguhsungguh dalam implementasi kebijakan berdampak pada penyediaan sumber daya. 
- Faktor Komunikasi; Informasi dan transmisi yang jelas tidak menjamin pelaksanaan/implementasi berjalan dengan baik. Faktor komunikasi yang sudah terpenuhi tanpa di dukung oleh disposisi implementor, membuat kebijakan tidak berjalan. Namun dalam penanganan bencana erupsi gunung Sinabung, diskresi perlu dilakukan mengingat penanganan bencana menuntut respon yang cepat. Kenyataannya pemerintah tidak berani melakukan diskresi karena tidak adanya payung hukum yang mendasari dan takut terjebak masalah hukum.

Dan masukan berupa saran sebagai berikut:

- Untuk mengubah disposisi/sikap (khususnya respon) implementor kebijakan di daerah, yakni pemerintah daerah, pemerintah pusat perlu membuat sistem reward and punishment terkait implementasi kebijakan penanggulangan bencana di daerah-daerah. Salah satunya dengan membuat aturan yang menekan pemerintah daerah dengan alokasi keuangan pusat daerah, dimana implementasi kebijakan penanggulangan bencana menjadi prasyarat terhadap pembagian alokasi keuangan tersebut. Diharapkan dengan aturan tersebut, pemerintah daerah mau megambil sikap tegas dalam implementasi kebijakan penanggulangan bencana di daerahnya masing-masing.

- Pemerintah pusat perlu melakukan kajian terhadap Permendagri No 46 Tahun 2008 terkait pembentukan Badan Penanggulangan Bencana Daerah yang bersinggungan dengan Peraturan Kepala Badan Nasional Penanggulangan Bencana No. 3 Tahun 2008. Atau membuat BPBD secara langsung berada di bawah BNPB (perpanjangan tangan).

- Klasifikasi terhadap daerah menimbulkan polemik terkait pembentukan Badan Penaggulangan Bencana Daerah yang harus mengikuti prasyarat terkait kemampuan sumber daya, kebutuhan daerah dan tingkat resiko bencana. Apabila suatu daerah memilki tingkat resiko bencana tinggi namun kemampuan sumber dayanya terbatas, tentu pemerintah daerah akan bingung. Pemberian Klasifikasi ini perlu di kaji ulang.

\section{Daftar pustaka}

[1] Budi Winarno. (2008). Kebijakan publik, teori dan proses. Jakarta: Media Pressindo Creswell, John W. (2010). Research design, pendekatan kualitatif, kuantitatif, dan mixed.Yogyakarta:Pustaka Pelajar

[2] `Edward III, George C. (1980). Implementing public policy.Washington DC: Congressional Quarterly Inc Grindle,

[3] Merilee S. (1980). Politic and policy implementation in the third world.New Jersey: Princeton University Press

[4] Kodoatie, Robert. (2006). Analisa ancaman bencana hydro-meteorologis di indonesia. Yogyakarta: Sheep Indonesia

[5] Lexy Moleong.(1997). Metode penelitian kualitatif. Bandung: PT Remaja Rosdakarya

[6] Michael Hill \& Peter Hupe. (2002). Implementing public policy: governance in theory and in practice London: Sage Publications

[7] Parson, Wayne.(2006). Public policy, pengantar teori dan praktek analisis kebijakan. Jakarta: Kencana Riant Nugroho. (2008). Public policy. Jakarta: PT Elex Media Komputindo

[8] Parson, Wayne. (2012). Public policy (Edisi Keempat Revisi). Jakarta : PT Elex Media Komputindo

[9] (2013). Metode penelitian kebijakan.Yogyakarta:Pustaka Pelajar

[10] Parson, Wayne .(2014).Kebijakan publik di negara-negara berkembang. Yogyakarta: Pustaka Pelajar

[11] Safri Nugraha, dkk.(2007). Hukum administrasi negara.Depok: Center For Law and Good Governance Studies (CLGS-FHUI)

[12] Syamsul Maarif. (2012). Pikiran dan gagasan; penanggulangan bencana di Indonesia. Jakarta: BNPB

[13] Tjokroamidjojo, Bintoro dan AR, Mustopadidjaja, (1988).Kebijaksanaan dan administrasi pembangunan, perkembangan, teori dan penerapan.Jakarta: LP3ES

\section{Undang-Undang dan Peraturan}

[1] Undang-Undang Nomor 24 Tahun 2007 Tentang Penanggulangan Bencana

[2] Peraturan Pemerintah No 21 Tahun 2008 Tentang Penyelenggaraan Penanggulangan Bencana

[3] Peraturan Pemerintah No 22 Tahun 2008 Tentang Pendanaan dan Pengelolaan Bencana

[4] Peraturan Pemerintah No 23 Tahun 2008 Tentang Peran Serta Lembaga Internasional dan Lembaga

[5] Asing Non Pemerintah Dalam Penanggulangan Bencana

[6] Peraturan Kepala (Perka) Badan Nasional Penanggulangan Bencana Nasional No 3 Tahun 2008 Tentang

[7] Pembentukan Badan Penanggulangan Bencana Daerah

[8] Peraturan Menteri Dalam Negeri (Permendagri) No. 46 Tahun 2008 tentang Pedoman Organisasi dan Tata Kerja BPBD

[9] Peraturan Kepala (Perka) BNPB No. 3 Tahun 2008 tentang Pedoman Pembentukan BPBD 


\section{Jurnal}

[1] Agus Rachmat. Manajemen dan mitigasi bencana.Kepala Badan Pengendalian Lingkungan Hidup Daerah (BPLHD) Provinsi Jawa Barat

[2] James E. Garret. (1993). Public administration and policy implementation: a social work perspektive.International Journal Of Public Administration, hal. 52-53

[3] Khan, Himayatullah, (2008). Disaster management cycle a theoretical approach.Pakistan: Institution Information Of Technology Abbottabad

[4] Lilik Kurniawan. (2008). Kajian penilaian bahaya tanah longsor provinsi sumatera utara. Jurnal Sains dan Teknologi Indonesia Vol. 10 No. 2 Agustus 2008 Hal. 90-98

[5] Syamsul Maarif et al., (2012). Kontestasi pengetahuan dan pemaknaan tentang ancaman bencana alam.Jurnal Penanggulangan Bencana Volume 3 Nomor 1, Tahun 2012, hal 1-13

\section{Lain-lain}

[1] Melindungi Para Korban Bencana Alam.Buku Panduan Operasional IASC (Komite Tetap Antar Lembaga) tentang Hak-hak Asasi Manusia (HAM) dan Bencana-bencana Alam. Brookings-Bern Project on Internal Displacement 1775 Massachusetts Avenue, NW Washington, DC 20036

[2] Memburu Letusan Sinabung. Geomagz, Majalah Geologi Populer, Vol. 3 No. 4 Desember 2013.Hal. 68ᄀ82. Badan Geologi-Kementerian Energi dan Sumber Daya Mineral

[3] Dari Wasior, Mentawai, hingga Merapi.Gema BNPB; Ketangguhan Bangsa dalam Menghadapi Bencana.Vol.2 No. 1 Maret 2011. BNPB Jakarta

[4] Rochyati (2012, Desember 20) pendekatan dan teori - teori implementasi Kebijakanpublikhttp://rochyati-w-t-fisip.web.unair.ac.id/artikel

\section{Website}

[1] www.bnpb.go.id

[2] www.karokab.go.id

[3] http://otda.kemendagri.go.id/

[4] www.rri.co.id

[5] www.sumutpos.co.id

[6] www.esdm.go.id/

[7] http://video.news.viva.co.id/read/31152-pengungsi-sinabung-keluhkan-mck-darurat_1

[8] http://www.mpbi.org/content/pembentukan-bpbd-berdasar-permendagri-462008-dan-perka-bnpb-32008 